\title{
$\gamma \delta$ T Cells Attenuate Bleomycin-Induced Fibrosis through the Production of CXCL10
}

\author{
Derek A. Pociask, ${ }^{*}$ Kong Chen, ${ }^{*}$ Sun Mi Choi, ${ }^{*}$ \\ Tim D. Oury, ${ }^{\dagger}$ Chad Steele, ${ }^{\ddagger}$ and Jay K. Kolls* \\ From the Department of Genetics, ${ }^{*}$ Louisiana State University \\ Health Sciences Center, New Orleans, Louisiana; the Department \\ of Pathology, ${ }^{\dagger}$ University of Pittsburgh School of Medicine, \\ Pittsburgh, Pennsylvania; and the Department of Medicine, \\ University of Alabama, Birmingham, Alabama
}

$\gamma \delta \mathrm{T}$ cells are a subset of $\mathrm{T}$ cells associated with epithelial mucosal tissues and play a prominent role in both promoting and dampening inflammatory responses to pathogens; in addition, they strongly mediate epithelial repair. By using a bleomycin model of pulmonary fibrosis, we found that $\gamma \delta$ T-cell populations dramatically increased after bleomycin administration. To determine the importance of these cells, we exposed mice lacking the $\delta$ chain of the $\gamma \delta$ T-cell receptor ( $\gamma \delta$ knockout [KO]) to bleomycin. Pulmonary fibrosis was more severe in $\gamma \delta \mathrm{KO}$ mice, as measured by collagen deposition (hydroxyproline) and histopathological features. Furthermore, there was no evidence of resolution of the fibrotic response up to 45 days after bleomycin therapy. In contrast to control mice, $\gamma \delta$ KO mice had decreased concentrations of IL-6, granulocyte colony stimulating factor, chemokine CXC ligand (CXCL) 1 , and interferon inducible protein 10/CXCL10. In vitro culture of $\gamma \delta \mathrm{T}$ cells purified from lungs 17 days after bleomycin exposure (a time of peak influx of these cells) demonstrated that $\gamma \delta \mathrm{T}$ cells produced substantial quantities of all four of these cytokines, suggesting that $\gamma \delta \mathrm{T}$ cells are a predominant source of these proteins. To demonstrate that $\gamma \delta$ T cells are effector cells in the fibrotic response, we performed adoptive transfer experiments with $\gamma \delta \mathrm{T}$ cells sorted from bleomycin-treated lungs; these cells were sufficient to resolve fibrosis in $\gamma \delta \mathrm{KO}$ mice and restore $\mathrm{CXCL10}$ levels comparable to wild-type mice. Furthermore, overexpression of CXCL10 in the lung decreased the severity of fibrosis seen in the $\gamma \delta \mathrm{KO}$ mice. Finally, adoptive transfer of $\gamma \delta \mathrm{T}$ cells from $\mathrm{CXCL10}^{-/-}$mice failed to reverse the severe fibrosis in $\gamma \delta$ KO mice. These results indicate that $\gamma \delta \mathrm{T}$ cells promote the resolution of fibrosis through the production of CXCL10. (Am J Pathol 2011, 178:1167-1176; DOI: 10.1016/j.ajpath.2010.11.055)

Both idiopathic pulmonary fibrosis (IPF) and drug-induced pulmonary fibrosis can be progressive life-threatening diseases characterized by fibroblast accumulation and excessive collagen deposition, leading to impaired lung function with decreased gas exchange and ultimately respiratory failure. The etiology of IPF is unknown (and, thus, idiopathic), and it has a high incidence (42.7/ $100,000),{ }^{1}$ poor survival (3- to 5-year median), and few limited therapeutic approaches. ${ }^{2,3}$

Pulmonary fibrosis is also a complication of autoimmune diseases (eg, systemic lupus erythematosus), rheumatoid arthritis, and drugs (eg, bleomycin). In fact, pulmonary fibrosis is the dose-limiting toxic effect of bleomycin in humans; even with careful dosing, bleomycin can lead to end-stage fibrosis, requiring lung transplantation. ${ }^{4}$ The initial response to injury from a fibrotic agent such as bleomycin is the induction of a strong inflammatory response, including neutrophils, macrophages, and T cells. Several studies have implicated $T$ cells in the development and progression of fibrosis. In humans, $T$ cells are found in high abundance in lung biopsy specimens, ${ }^{5}$ lavage fluid, ${ }^{6}$ and circulating blood ${ }^{7}$ in patients with IPF. By using mouse models, thymectomized mice ${ }^{8}$ or mice treated with steroids ${ }^{9}$ or anti-CD3 antibodies all show reduced fibrosis, ${ }^{8}$ suggesting that $T$ cells are required for fibrosis. However, mice with severe combined immunodeficiency lacking $T$ and $B$ cells and nude mice lacking $T$ cells show no difference in bleomycin-induced disease, causing a debate over the role of T cells. ${ }^{10,11} \mathrm{~A}$ limitation of the previously described studies is that the approaches described do not address the specific role

Supported by NIH grant R01-HL079142.

Accepted for publication November 18, 2010.

Supplemental material for this article can be found at http://ajp. amjpathol.org or doi:10.1016/j.ajpath.2010.11.055.

Address reprint requests to Derek A. Pociask, Ph.D., Department of Genetics, Louisiana State University Health Sciences Center, 533 Bolivar St, Clinical Science Research Building 656, New Orleans, LA 70112. E-mail: dpocia@Isuhsc.edu. 
of T-cell subsets that may be profibrotic or antifibrotic. Thus, the deletion of both protective and beneficial T-cell populations may reveal no difference in models of fibrosis. In support of this statement, there is evidence that fibrosis may be perpetuated by helper T cell (Th) subtype bias. Generally, a Th2 bias is profibrotic. Tissues from patients with IPF have generally higher levels of IL-4, IL-5, and IL-13. ${ }^{12,13}$ In mouse models, mice overexpressing GATA-3 (a Th2 transcription factor $)^{14}$ as well as mice in which T-bet (a Th1 transcription factor) is knocked out, ${ }^{15}$ both demonstrate greater sensitivity to fibrotic agents. ${ }^{14,15}$ More recently, data suggest that the Th17 response may also be profibrotic because IL-17A was increased in the lavage fluid of patients with $\mathrm{IPF}^{16}$ and $I /-17 a^{-1-}$ mice were less susceptible to bleomycin-induced inflammation ${ }^{16,17}$ and fibrosis. ${ }^{16}$

$\gamma \delta \mathrm{T}$ cells are generally found in low numbers in "normal" lung (approximately 1\%) and are found in close proximity to epithelial mucosal cells and alveoli. ${ }^{18}$ Because of their location, $\gamma \delta$ T cells are one of the first lines of defense against infection and appear to play a distinctive role in epithelial response to injury, repair, and homeostasis. For example, they are critical for epithelial wound repair in the skin. ${ }^{19}$ Interestingly, patients with IPF have decreased $\gamma \delta \mathrm{T}$ cells in their bronchoalveolar lavage (BAL) fluid. ${ }^{20}$ In lung injury models, such as chlorine gas ${ }^{21}$ or ozone ${ }^{22} \gamma \delta$ T cells are required for neutrophil influx and epithelial repair. Furthermore, $\gamma \delta$ T-cell populations increase in response to bleomycin injury. ${ }^{23}$ For chronic Bacillus subtilis infection, mice lacking $\gamma \delta$ T cells demonstrated an enhanced fibrotic phenotype. ${ }^{24}$ Because of the potential role of these cells in epithelial repair (a process that has been hypothesized to be critical for the prevention of fibrosis), we hypothesized that $\gamma \delta$ T cells are critical for resolving fibrogenic insults in the lung.

The current study demonstrates that $\gamma \delta$ T cells play an integral role in the response to bleomycin. Lung $\gamma \delta$ T-cell populations increased during the course of injury. In vitro $\gamma \delta$ T cells recruited to the lung spontaneously produce large amounts of IL-6, chemokine CXC ligand $(C X C L) 1$, granulocyte colony stimulating factor (G-CSF), and the antifibrogenic chemokine CXCL10, also known as IP-10. Furthermore, $\gamma \delta \mathrm{TCR}^{-1-}$ mice showed progressive fibrosis in response to bleomycin and diminished levels of CXCL10 in vivo. Overexpression of CXCL10 resulted in significantly attenuated fibrosis in $\gamma \delta \mathrm{TCR}^{-1-}$ mice. To confirm that $\gamma \delta$ T cells mediate antifibrotic responses via a CXCL10-dependent mechanism, adoptive transfer experiments were performed with $\gamma \delta$ T cells from wild-type (WT) or $\mathrm{C} x \mathrm{C} / 10^{-1-}$ mice. Adoptive transfer of WT T cells into $\gamma \delta$ $\mathrm{TCR}^{-1-}$ mice significantly reduced pulmonary fibrosis in response to bleomycin, whereas $\gamma \delta \mathrm{T}$ cells from $\mathrm{CxC} / 10^{-1-}$ mice were unable to protect against fibrosis. Taken together, these data demonstrate the critical importance of $\gamma \delta \mathrm{T}$-cell production of CXCL10 and its role in the attenuation of the fibrotic response.

\section{Materials and Methods}

\section{Mice}

Specific pathogen-free mice were used in all experiments and housed in specific pathogen-free conditions within animal care facilities at Children's Hospital of Pittsburgh, Pittsburgh, PA, or Louisiana State University Health Sciences Center, New Orleans, LA. All mouse experiments were approved by the University of Pittsburgh or the Louisiana State University Institutional Animal Care and Use Committee. B6.129S4-CxC/10 tm1Adl/J $_{\text {[CXCL10 }}$ knockout (KO) mice], B6.129P2-Tcrb ${ }^{\text {tm } 1 \text { Mom } / J ~(T c r b ~ K O ~}$ mice) and appropriate age- and sex-matched C57BL/6 controls were purchased from Jackson Laboratory (Bar Harbor, ME). B6.129P2-Tcrd ${ }^{\text {tm } 1 M o m}(\gamma \delta \mathrm{KO})$ mice were bred in-house and backcrossed over 10 generations with C57BL/6 mice. For all experiments, male mice (aged 6 to 8 weeks) were used.

\section{Oropharyngeal Administration of Bleomycin}

All treatments were performed using the oropharyngeal aspiration-tongue pull technique on isoflurane-anesthetized mice, as previously described. ${ }^{25,26}$ Bleomycin USP (Hospira Pharmaceuticals Lake Forest, IL) was administered (2-U/kg body weight) in sterile PBS (100 $\mu \mathrm{L})$. Adenovirus encoding CXCL10 or green fluorescent protein (adenovirus control) was administered in $100 \mu \mathrm{L}$ of sterile saline at a concentration of $10^{8}$ plaque-forming units. ${ }^{27}$ Lungs were harvested at days 3 to 45 for evaluation of pulmonary fibrosis.

\section{Lung Histological Features}

Animals were sacrificed by i.p. injection of $0.9-\mathrm{ml} / \mathrm{kg}$ body weight ketamine, followed by exsanguination through the renal artery. After exposing the chest cavity, the right main bronchus was sutured at the base of the main stem and the right lung was excised and snap frozen in liquid nitrogen and stored at $-70^{\circ} \mathrm{C}$ for protein analysis. The left lung was inflated with $10 \%$ neutralbuffered formalin (Sigma Chemical Co, St Louis, MO) at a pressure of $25 \mathrm{~cm} \mathrm{H}_{2} \mathrm{O}$ for 15 to 20 minutes, removed from the animal, and placed in fresh $10 \%$ neutral-buffered formalin for 16 to 20 hours at $4^{\circ} \mathrm{C}$ before processing and paraffin embedding. For histological analysis, $5-\mu \mathrm{m}$ sections were cut and stained with hematoxylin-eosin. The severity of disease was scored by a pathologist (T.D.O) blinded to the groups, as previously described. ${ }^{28}$ Individual fields were scored at $\times 400$ magnification, with a minimum of 20 fields per slide. To be included, each field had to contain greater than $50 \%$ alveoli. Scoring in each field was based on the percentage of alveolar tissue with interstitial fibrosis, according to the following scale: 0 indicates no fibrosis; 1 , up to $25 \%$ fibrosis; $2,25 \%$ to $50 \%$ fibrosis; $3,50 \%$ to $75 \%$ fibrosis; and $4,75 \%$ to $100 \%$ fibrosis. To visualize collagen, Gomori's trichrome staining (Sigma Chemical Co) was performed according to manufacturer's instructions. 


\section{Bronchoalveolar Lavage}

Tracheas were exposed and cannulated. Bronchoalveolar lavage fluid was collected in $10 \times 1-\mathrm{ml}$ aliquots of sterile PBS supplemented with 0.6- $\mathrm{mmol} / \mathrm{L}$ EDTA. Aliquots were combined and centrifuged for 10 minutes at $500 \times g$. Cells were resuspended in $1 \mathrm{ml}$ of PBS-EDTA and counted. A total of $1 \times 10^{5}$ cells were spun onto a glass slide and stained for differential counting.

\section{Protein Analysis}

All protein analysis was performed on lung homogenate. Briefly, lungs were homogenized in $1 \mathrm{ml}$ of PBS with complete miniprotease inhibitor cocktail (Roche Scientific, Indianapolis IN) using a Polytron handheld homogenizer (Daigger, Vernon Hills, IL). Lung homogenate was centrifuged at $12,000 \times g$ for 15 minutes, and supernatant was stored at $-80^{\circ} \mathrm{C}$ for later cytokine analysis. G-CSF, granulocyte macrophage stimulating factor, interferon- $\gamma$, IL-1a, IL-1b, IL-2, IL-4, IL-5, IL-6, IL-7, IL-9, IL-10, IL-12 p70, IL-13, IL-15, IL-17, CXCL10/IP-10, CXCL1/ CXCL1 chemokine (c-c motif) ligand 5 (CCL5), macrophage inflammatory protein 1, and tumor necrosis factor $\alpha$ were analyzed using Luminex (Millipore, Billerica, MA) on a reader (Bioplex, Bio-Rad, Hercules, CA). Data were analyzed using computer software (Bioplex manager software).

\section{Flow Sorting and Cytometry}

To examine whole lung T-cell populations, lungs were isolated, minced, and placed in RPMI 1640 medium with $5 \%$ bovine serum albumin. Collagenase was added, and lungs were digested for 30 minutes at $37^{\circ} \mathrm{C}$ in an orbital shaker. Digests were passed through 70- and 40- $\mu \mathrm{m}$ filters and centrifuged (for 10 minutes at $500 \times$ g). Cells were resuspended in 9 ml of RPMl 1640 medium, layered over $5 \mathrm{ml}$ of Ficoll (GE Healthcare, Waukesha, WI), and spun for 15 minutes at $1350 \times g$. The interphase was removed, placed in RPMI 1640 media, and centrifuged for 10 minutes at $500 \times g$. For flow sorting, cell pellets were resuspended in PBS containing $2 \%$ fetal bovine serum. Cells were stained with fluorochrome-conjugated primary antibodies for 60 minutes on ice and washed twice with PBS-fetal bovine serum. Analysis was performed by gating on the predominantly lymphocytic population based on size using forward-and-side scatter. Autofluorescence was accounted for by running unstained cells and subtracting the fluorescence as background. Nonspecific binding was controlled by running isotype controls. For cell sorting, the delta chain of the TCR was detected using the GL3 antibody (BD Pharmingen, San Diego, CA). $\gamma \delta$ T cells were sorted as $\mathrm{GL}^{+} /$ $\mathrm{TCR}^{\beta-}$ cells. Purity was checked by reanalyzing sorted cells and gating on $\mathrm{GL}^{+}$cells. For adoptive transfer, cells were sorted from whole lung 17 days after bleomycin treatment and verified to be greater than 95\% pure based on the sorting. Non- $\gamma \delta$ T cells were all considered to be $\mathrm{GL}^{-}$cells.

\section{PCR for $\gamma \delta$ T-Cell Subtyping}

The RNA was collected from sorted cells using a modified Trizol (Invitrogen, Carlsbad, CA) RNA extraction protocol to extract RNA from a few cells. Briefly, cells were placed in Trizol, and chloroform was added. After centrifugation (12,000 $\times g, 15$ minutes) the aqueous layer was removed. Five $\mu \mathrm{g}$ of glycogen was added, and the RNA was precipitated after the addition of isopropyl alcohol and centrifugation (12,000 $\times g, 10$ minutes). The RNA was washed twice in $75 \%$ ethanol. The RNA was quantified by nanodrop, reverse transcribed using SuperScript III (Invitrogen), and verified by RT-PCR amplification of the $\beta$-actin housekeeping gene.

The subtype of $\gamma \delta \mathrm{T}$ cell was determined by RT-PCR amplification with reagents (Clonetech) using published primers $^{29}$ : C $\gamma$, 5'-CTTATGGAGATTTGTTTCAGC-3'; V $\gamma 1 / 2$, 5'-ACACAGCTATACATTGGTAC-3'; $V \gamma$ 2, 5'-CGGCAAAAAACAAATCAACAG-3'; $\quad V \gamma 4, \quad$ 5'-TGTCCTTGCAACCCCTACCC-3'; $V \gamma 5$, 5'-TGTGCACTGGTACCAACTGA-3'; $V \gamma 6$, 5'-GGAATTCAAAAGAAAACATTGTCT-3'; and $V \gamma 7$, 5'AAGCTAGAGGGGTCCTCTGC-3'. The PCR conditions were verified by observing the expected $\vee \gamma 5$ subset in mouse skin cells.

\section{Lung Collagen Assay (Hydroxyproline)}

To estimate the total amount of collagen in the lungs, hydroxyproline was measured as previously described. ${ }^{30}$ Briefly, right lungs were removed and homogenized in $6 \mathrm{~N}$ $\mathrm{HCl}$ at $110^{\circ} \mathrm{C}$ overnight. Precipitates were removed by centrifugation. Supernatants were dried overnight and dissolved in distilled water. Each sample was tested in duplicate; $50 \mu \mathrm{L}$ of chloramine $\mathrm{T}$ in acetate buffer $(\mathrm{pH}$, 6.0), $50 \mu \mathrm{L}$ of perchloric acid, and $50 \mu \mathrm{L}$ of Erlich's reagent were added sequentially to each sample, as previously described, and absorbance was measured at $570 \mathrm{~nm}$.

\section{Statistics}

All data are represented as the mean \pm SD. Significance was determined using either an unpaired $t$-test when comparing two groups or a one-way analysis of variance with Tukey's post hoc test when comparing multiple groups. All statistics were calculated using computer software (GraphPad Prism 4).

\section{Results}

\section{$\gamma \delta$ T-Cell-Deficient Mice Have Aggravated Bleomycin-Induced Lung Injury and Fibrosis}

$\gamma \delta \mathrm{T}$ cells have been strongly implicated in epithelial wound repair in skin. ${ }^{19}$ To understand their role in bleomycin-induced lung injury, we examined the kinetics of infiltrating interstitial $\gamma \delta$ T cells in lung tissue after administration of bleomycin. $\gamma \delta$ T cells were identified as $\mathrm{GL}^{+}$ $\mathrm{CD}^{+}$cells (Figure 1A), and staining specificity was determined by running Armenian hamster isotype control 

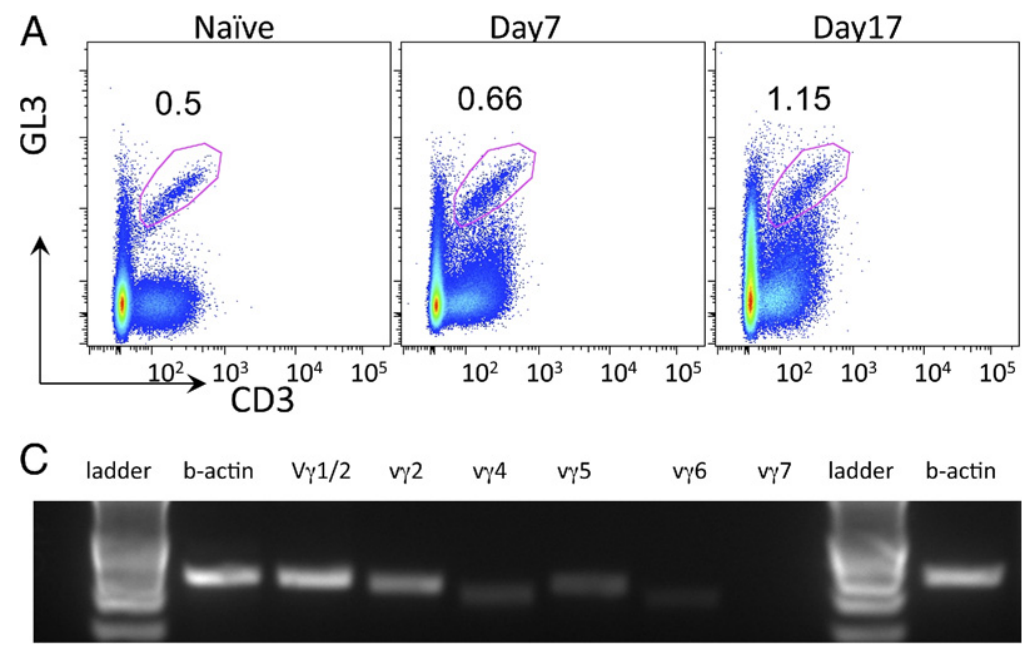

B

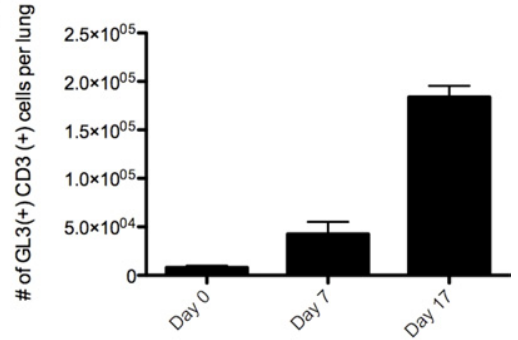

Figure 1. $\gamma \delta \mathrm{T}$ cells infiltrate the lung in response to bleomycin. A: Flow cytometric analysis of $\gamma \delta$ T cells from whole lung homogenate of $\mathrm{C} 57 \mathrm{BL} / 6$ treated with bleomycin. Cells were gated based on size and then analyzed for their expression of TCR $\gamma \delta$ and CD3. Values indicate the percentage of cells and are representative of three independent experiments ( $n=3$ to 5 mice per experiment). B: Analysis of $\boldsymbol{\gamma} \boldsymbol{\delta}$ T-cell populations at different intervals after bleomycin treatment demonstrates an increase in the number of $\boldsymbol{\gamma} \boldsymbol{\delta}$ T cells. C: RNA was extracted from sorted $\mathrm{GL}^{+}{ }^{+} \mathrm{CD}^{+}$cells, and RT-PCR analysis demonstrated a polyclonal population of $\gamma \delta \mathrm{T}$ cells. (see Supplemental Figure S1 at http://ajp.amjpathol.org). In WT C57BL/6 mice, interstitial $\gamma \delta$ T-cell populations substantially increased from day 1 to 17 from less than $10^{4}$ cells in naive mice to $2 \times 10^{5}$ cells per mouse lung, as shown in Figure 1B. To identify which subsets of $\gamma \delta \mathrm{T}$ cells were found in the lung after bleomycin exposure, PCR was performed on flow-sorted cells from day 14. As seen in Figure $1 C$, bleomycin induced a polyclonal $\gamma \delta$ T-cell response, with $V_{\gamma} 1, V_{\gamma} 2, V_{\gamma} 4, V_{\gamma} 5$, and $V_{\gamma} 6$ populations all being identified.

To understand the biological significance of these cells in bleomycin-induced injury and fibrosis, mice deficient in $\gamma \delta \mathrm{T}$ cells $(\gamma \delta \mathrm{KO})$ mice were administered bleomycin. As previously shown in this model, WT C57BL/6 mice showed a time-dependent increase in hydroxyproline, a measurement of collagen deposition in the lung with some degree of resolution by day 45 (Figure 2A). In contrast to this response, $\gamma \delta \mathrm{KO}$ mice showed similar levels of hydroxyproline in lung tissue as WT mice at day 7 , followed by substantially greater increases up to day 45 (Figure 2A). Furthermore, there was no evidence of resolution of fibrosis in the $\gamma \delta \mathrm{KO}$ mice. In comparison,
TCR $\beta^{-1-}$ mice did not show any perturbations in fibrosis and were not different from WT mice 21 days after bleomycin exposure (see Supplemental Figure S2 at http:// ajp.amjpathol.org). The increases in hydroxyproline were also supported by histological analysis, which demonstrated that mice deficient in $\gamma \delta$ T cells had thickened alveolar septa and ablation of alveolar spaces on days 14 (Figure 2, B and C) and 28 after bleomycin treatment compared with WT mice (Figure 2, E and F); in addition, $\gamma \delta \mathrm{KO}$ mice demonstrated a significantly reduced inflammatory infiltrate. Blinded scoring ${ }^{28}$ of the severity of fibrotic lesions revealed that $\gamma \delta \mathrm{KO}$ mice had significantly higher histological scores at 14 and 28 days after instillation of bleomycin (Figure 2, D and G).

To examine if $\gamma \delta \mathrm{T}$ cells regulate early inflammatory events in the lung after bleomycin treatment, WT and $\gamma \delta$ $\mathrm{KO}$ mice were treated with bleomycin and sacrificed at 3 and 7 days after instillation for BAL fluid and cytokine analysis. The WT mice showed significant increases in total inflammatory cells in the BAL fluid at both 3 and 7 days (Figure 3, A and B), with both increases in neutrophil and macrophage recruitment compared with vehicle

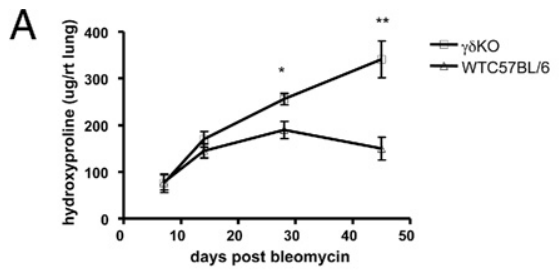

Figure 2. Histological and biochemical analysis of bleomycin-induced pulmonary fibrosis in WT and $\gamma \delta \mathrm{KO}$ mice. A: $\gamma \delta \mathrm{KO}$ mice have more collagen deposition than WT mice. Hydroxyproline content was measured in the lungs of $\gamma \delta \mathrm{KO}$ and WT mice at 7, 14, 28, and 45 days after bleomycin administration. B and C: Lungs of C57BL/ 6 and $\gamma \delta \mathrm{KO}$ mice 14 days after bleomycin exposure. $\mathbf{D}$ and $\mathbf{F}$ : Severity of disease score was determined as explained in the Lung Histological Features subsection of Materials and Methods. Scores are based on a scale from 0 to 4 and are represented as the mean $\pm \operatorname{SD}(n=5)$. $\mathbf{E}$ and $\mathbf{G}$ : Data at 28 days after exposure. Data are expressed as hydroxyproline content per right lung. Data are representative of two independent experiments $(n=5$ mice per experiment $) .{ }^{* * *} P<0.01$,
${ }_{* * * * *} P<0.001$
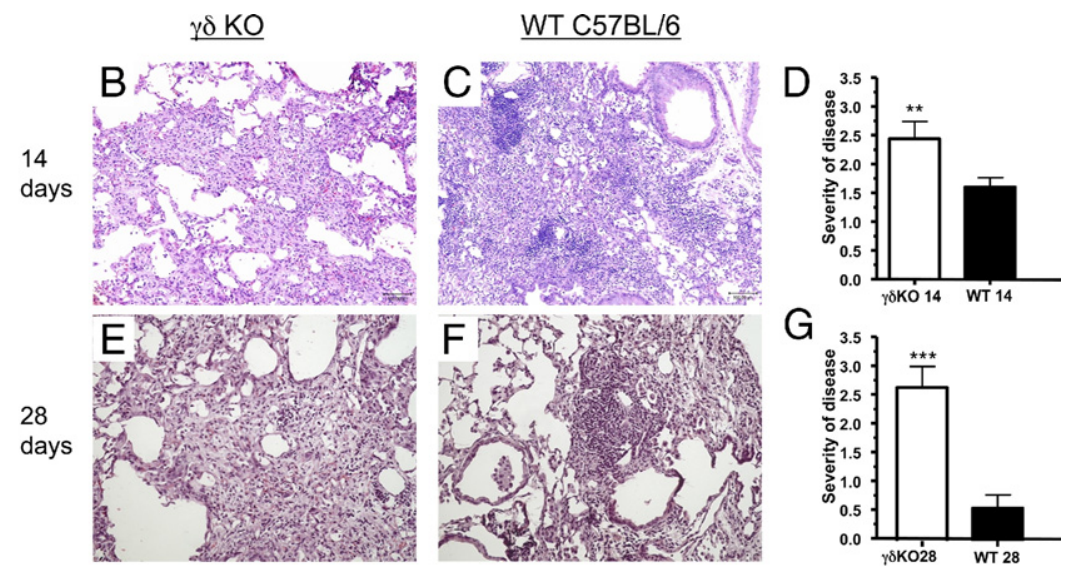
A

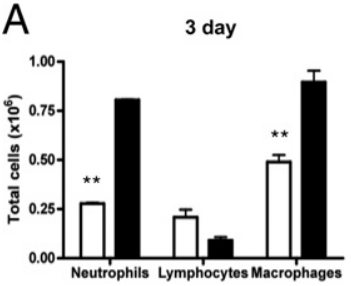

C

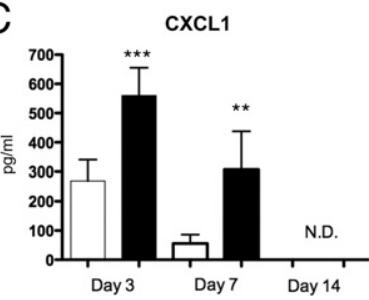

E

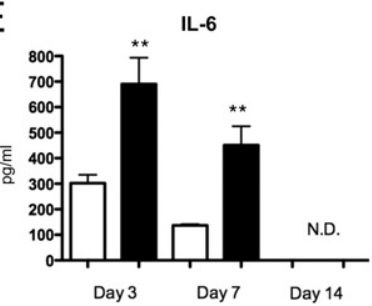

B

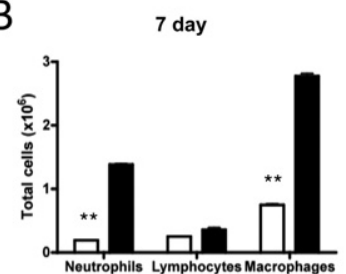

D

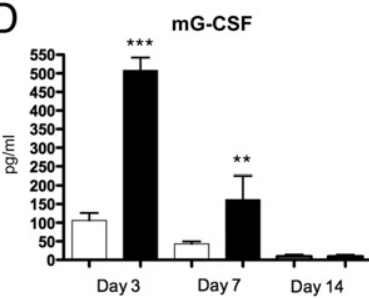

$\mathrm{F}$

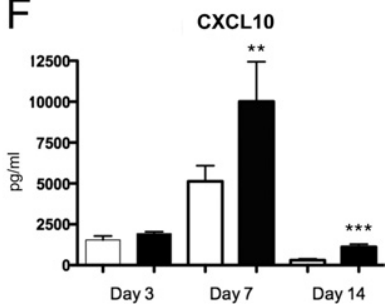

Figure 3. $\gamma \delta \mathrm{T}$-cell $\mathrm{KO}$ mice have decreased inflammation and inflammatory cytokines in response to bleomycin. A and B: The BAL fluid was taken from $\gamma \delta \mathrm{KO}$ (white bars) or C57BL/6 WT controls (black bars) at 3 and 7 days after bleomycin exposure, and differential cell counts were performed. Bleomycin-induced inflammation compared with PBS controls (data not shown). The results indicate the mean $\pm \mathrm{SD}$ ( $n=5$ mice per group). C-F: Cytokines from supernatants of whole lung homogenate were analyzed from $\gamma \delta \mathrm{KO}$ and WT controls after bleomycin treatment. C: CXCL1 (KC) was increased in WT mice vs gdKO at both days 3 and 7 and none determined (N.D.) at day 14. D: Mouse G-CSF. E: IL-6. F: CXCL10 (IP-10) was significantly increased in WT vs gdKO in a later fashion with significant differences at days 7 and 14 . Data represent the mean \pm SD from at least two independent experiments ( $n=5$ mice per time point). ${ }^{* * *} P<0.01,{ }^{* * * *} P<0.001$.

controls, which showed $0.92 \pm 0.1 \times 10^{5}$ macrophages. In stark contrast, bleomycin-exposed $\gamma \delta \mathrm{KO}$ mice showed significantly fewer total cells in the BAL fluid at both $3\left(0.95 \pm 0.12 \times 10^{6}\right)$ and $7\left(1.2 \pm 0.25 \times 10^{6}\right)$ days, with significantly fewer $(P<0.001)$ neutrophils and macrophages at these same points (Figure $3, A$ and $B$ ).
Because the cellular analysis of BAL fluid demonstrated that $\gamma \delta \mathrm{KO}$ mice have decreased inflammatory cell recruitment 3 to 7 days after bleomycin treatment compared with WT mice, we evaluated chemokine and cytokine production using whole lung homogenate, as previously described. ${ }^{25,26}$ Compared with WT mice, $\gamma \delta$ $\mathrm{KO}$ mice had significantly reduced levels of CXCL1, G-CSF, IL-6, and CXCL10 in BAL fluid (Figure 3C). Of the four cytokines/chemokines observed to be significantly different, CXCL10 was the only one still elevated by 14 days. We did not observe induction of IL-17 protein during this study.

\section{Adoptive Transfer of $\gamma \delta T$ Cells Attenuates Bleomycin-Induced Fibrosis in $\gamma \delta$ KO Mice}

Our data show that $\gamma \delta$ T cells are increased in the lung in response to bleomycin, and ablation of the $\gamma \delta$ TCR results in reduced acute inflammation but substantially worse fibrosis. To determine whether these cells are effector cells in the fibrotic response to bleomycin, we performed adoptive transfer experiments. Given the abundance and properties of $\gamma \delta$ T cells at 17 days after bleomycin treatment, we chose to use this point to collect and purify pulmonary $\gamma \delta \mathrm{T}$ cells for transfer. As previously stated, these cells are polyclonal and express TCR $\delta$ chains 1 through 6. Cells were gated as described in the Flow Sorting and Cytology subsection of Materials and Methods, and representative plots are found in Supplemental Figure S1 and Supplemental Figure S3 (at http://ajp. amjpathol.org). The $\gamma \delta \mathrm{KO}$ mice were instilled with bleomycin, followed 1 day later by oropharyngeal administration of purified $\gamma \delta$ T cells or non- $\gamma \delta \mathrm{T}\left(\mathrm{GL}^{-}\right)$cells $(50,000$ cells per mouse). Adoptive transfer of polyclonal $\gamma \delta \mathrm{T}$ cells significantly attenuated bleomycin-induced weight loss of $\gamma \delta \mathrm{KO}$ mice (Figure 4A). Furthermore, adoptive transfer of $\gamma \delta$ T cells significantly attenuated collagen deposition, whereas adoptive transfer of the non- $\gamma \delta$ population had no effect on attenuating bleomycin-induced increases in hydroxyproline (Figure 4B). Trichrome staining revealed that adoptive transfer of $\gamma \delta$ T cells induced
A

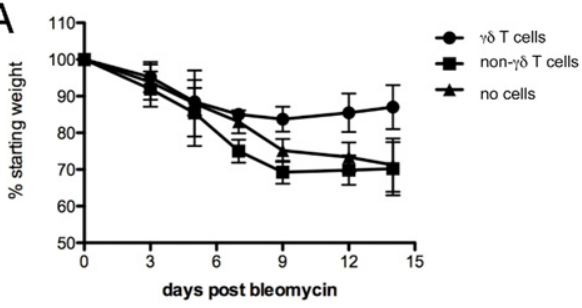

B
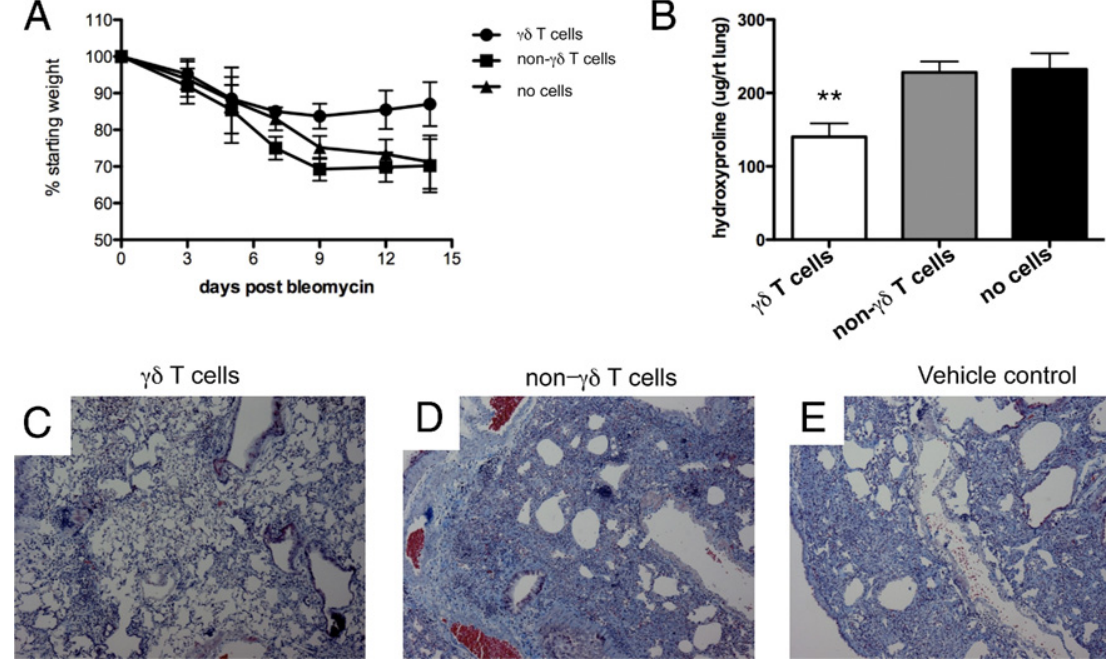

Vehicle control

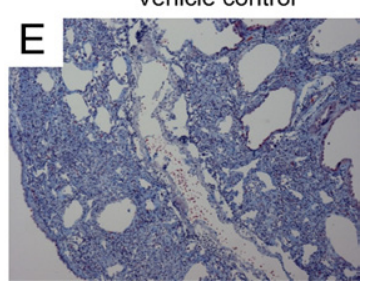

Figure 4. Adoptive transfer of $\gamma \delta \mathrm{T}$ cells reduced fibrosis in $\gamma \delta \mathrm{KO}$ mice. $\gamma \delta \mathrm{T}$ cells, non- $\gamma \delta \mathrm{T}$ cells, or vehicle control (PBS) was adoptively transferred 1 day after bleomycin exposure. A: Weight loss throughout the experiment. B: Hydroxyproline measured from lung homogenate 17 days after bleomycin exposure. Results represent the mean $\pm \mathrm{SD}(n=$ 5 mice per group) and are representative of three independent experiments. $\mathbf{C}$ through $\mathbf{E}$ : Representative trichrome staining demonstrates that $\gamma \delta$ T cells reduce fibrosis and collagen deposition in $\gamma \delta \mathrm{KO}$ mice (C) versus non- $\gamma \delta$ T cells $(\mathbf{D})$ or vehicle control cells $(\mathbf{E})$ at 17 days after bleomycin administration. ${ }^{* *} P<0.01$ 


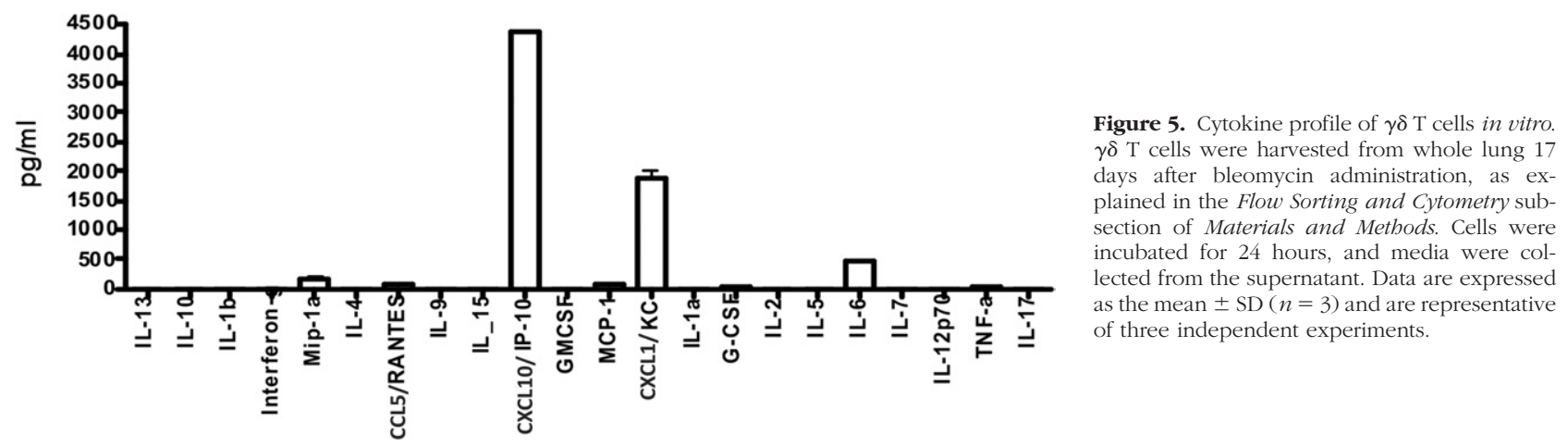

mild inflammation and reduced collagen deposition (Figure $4 C$ ) compared with adoptive transfer of non- $\gamma \delta \mathrm{T}$ cells (Figure 4D) or vehicle control (Figure 4E).

\section{$\gamma \delta T$ Cells Are Potent Producers of CXCL1, IL-6, and CXCL10}

To better understand how $\gamma \delta$ T cells regulate the fibrotic response to bleomycin, we cultured lung $\gamma \delta$ T cells from C57BL/6 mice 17 days after bleomycin exposure and characterized their growth factor production. Cells were plated at a density of 50,000 cells per well, and supernatants were collected after 24 hours of incubation and screened by an assay (Luminex). Lung $\gamma \delta$ T cells spontaneously produced substantial amounts of macrophage inflammatory protein-1-alpha, CCL5 (regulated on activation normal T cell expressed and secreted), CXCL1 (also known as keratinocyte chemoattractant), IL-6, and CXCL10 (IP-10) (Figure 5). However, there was no detectable IL-17 production from these cells. Among these cytokines and chemokines, production of CXCL10, a chemokine shown to regulate fibrosis, ${ }^{31,32}$ dominated. Thus, the in vitro production of this chemokine and the reduced levels of CXCL10 in $\gamma \delta \mathrm{KO}$ mice (Figure 4) strongly suggested that $\gamma \delta$ T cells may be a significant source of this chemokine in vivo.

To determine whether reduced production of CXCL10 in $\gamma \delta \mathrm{KO}$ was directly regulating the susceptibility to bleomycin-induced pulmonary fibrosis, we overexpressed CXCL10 in the lung using an adenoviral vector ${ }^{27} ; 7$ days after bleomycin treatment, WT or $\gamma \delta \mathrm{KO}$ mice were oropharyngeally instilled with adenovirus encoding CXCL10 or adenovirus encoding green fluorescent protein (control virus) $\left(1 \times 10^{8}\right.$ plaque-forming units per animal). This virus and concentration have previously efficiently produced CXCL10 over a 7-day period. ${ }^{27,33}$ Mice were sacrificed 17 days after bleomycin instillation. The $\gamma \delta \mathrm{KO}$ mice receiving adenovirus encoding CXCL10 had significantly less collagen compared with the $\gamma \delta \mathrm{KO}$ mice receiving adenovirus encoding green fluorescent protein after bleomycin treatment (Figure 6). These hydroxyproline levels were similar to those measured in WT mice receiving AdEFGP after bleomycin treatment. Wild-type mice receiving adenovirus encoding CXCL10 after bleomycin treatment had mildly reduced collagen levels; however, they were not significantly different from WT adenovirus encoding green fluorescent protein mice (Figure 6).

Because CXCL10 expression was sufficient to attenuate the accentuated fibrosis that develops in the $\gamma \delta \mathrm{KO}$ mice, the production of CXCL 10 by $\gamma \delta$ T cells was directly evaluated to determine its role in the protection offered by these cells. Lung CXCL10 levels were significantly increased by the adoptive transfer of $\gamma \delta$ T cells into $\gamma \delta \mathrm{KO}$ mice (Figure 7A). To specifically determine the contribution of CXCL10 from $\gamma \delta$ T cells, we purified $\gamma \delta$ T cells from CXCL10-deficient mice (CXCl10-1-) or WT mice 17 days after bleomycin administration. These cells were adoptively transferred directly into the lungs of $\gamma \delta \mathrm{KO}$ mice 1 day after bleomycin instillation. Although WT $\gamma \delta$ T cells showed reproducible decreases in lung hydroxyproline levels (compared with mice receiving no cells), CXCL10deficient $\gamma \delta$ T cells were incapable of restoring levels of CXCL10 (Figure 7A) and reducing the severe fibrosis seen in $\gamma \delta \mathrm{KO}$ mice (Figure 7B).

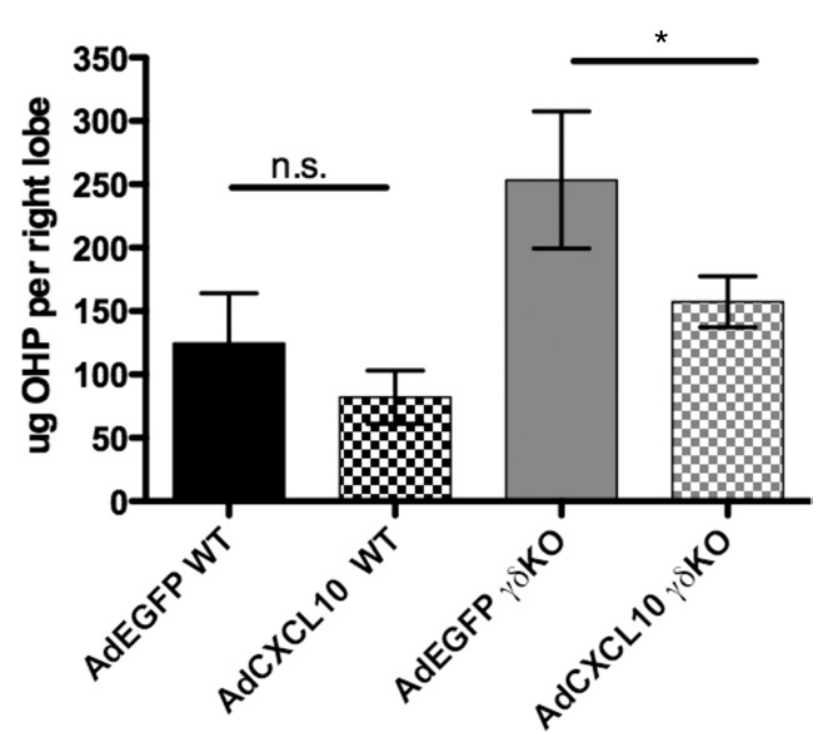

Figure 6. Adenoviral delivery of CXCL10 is sufficient to attenuate fibrosis in $\gamma \delta \mathrm{KO}$ mice. $\gamma \delta \mathrm{KO}$ and WT mice were tracheally instilled with adenovirus expressing Cxcl1O (adenovirus encoding CXCL10) or control virus expressing EGFP (adenovirus encoding green fluorescent protein) 5 days after bleomycin exposure. Mice were sacrificed at 17 days, and hydroxyproline (OHP) concentration was determined. The results are indicated as the mean $\pm \mathrm{SD}$ ( $n=$ at least 3 mice per group) and are representative of three independent experiments. ${ }^{*} P<0.05$. 
A

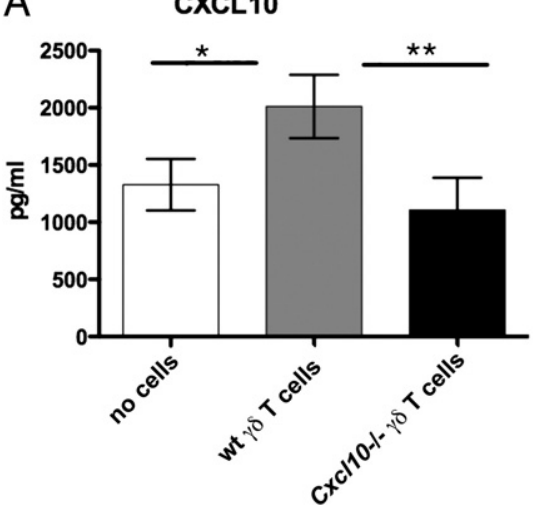

B

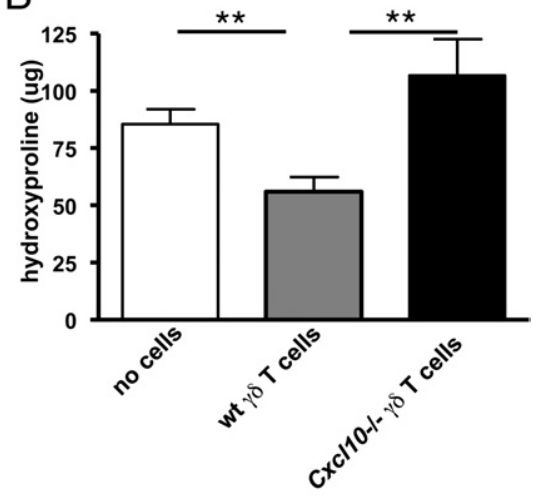

Figure 7. $\gamma \delta \mathrm{T}$ cells require CXCL10 to reduce col lagen deposition in $\gamma \delta$ KO mice. $\gamma \delta$ T cells harvested from Cxcl10 KO mice or WT background control mice were adoptively transferred into the lungs of $\gamma \delta$ KO mice after bleomycin exposure. A: The CXCL10 levels measured from lung homogenate 17 days after bleomycin instillation demonstrate $\gamma \delta \mathrm{T}$ cells from WT, but not Cxcl10 KO, mice. $\gamma \delta$ T cells were able to restore whole lung CXCL10 levels in $\gamma \delta \mathrm{KO}$ mice. B: Hydroxyproline levels measured from whole lung homogenate show that $\gamma \delta$ T cells from WT, but not Cxcl1O KO, mice are sufficient to reduce lung collagen. All data are represented as the mean $\pm \mathrm{SD}(n=$ 5 mice per group) and are representative of two repeated experiments. ${ }^{*} P<0.05,{ }^{* *} P<0.01$.

\section{Discussion}

The role of T cells in fibrosis is a topic of debate. ${ }^{34}$ In line with the current studies, there is growing literature that certain subsets of $T$ cells are beneficial because mice with severe combined immunodeficiency developed more severe fibrosis in response to asbestos, which was reduced on reconstitution with T cells. ${ }^{11}$ Furthermore, use of mice deficient in natural killer T cells ${ }^{35}$ or $\gamma \delta \mathrm{T}$ cells $^{36}$ has shown worsened fibrosis, suggesting that specific subsets of $\mathrm{T}$ cells are responsible for regulating fibrosis. Herein, we present evidence that a specific subset of $T$ cells (ie, $\gamma \delta$ T cells) are important in limiting and resolving fibrosis in a bleomycin model of lung injury. We found that $\gamma \delta \mathrm{T}$-cell populations are quickly induced after injury and that these populations increase over time. Functionally, $\gamma \delta \mathrm{T}$ cells appear to induce the initial inflammatory responses to bleomycin because mice lacking $\gamma \delta$ T cells had decreased inflammation and neutrophil migration. More interestingly, we observed that $\gamma \delta \mathrm{KO}$ mice developed more severe and progressive fibrosis, with no resolution by 45 days.

$\gamma \delta$ T cells are a predominant T-cell population in epithelial organs, such as skin and intestine, where they are required for proper wound healing. ${ }^{37,38}$ Although few are found in the lung, they are in close proximity to epithelial mucosal cells and in alveoli. ${ }^{18}$ Because of their location, $\gamma \delta$ T cells are one of the first lines of defense against infection and play a distinctive role in epithelial response to injury, repair, and homeostasis. ${ }^{39}$ This makes them interesting targets to study in the progression of a disease, such as IPF, because it occurs in response to epithelial injury. In a chronic $B$. subtilis infection, mice lacking $\gamma \delta$ T cells demonstrated an enhanced fibrotic phenotype ${ }^{24}$ because of enhanced inflammation. In support of our study, Braun et al ${ }^{36}$ recently showed that mice lacking $\gamma \delta$ T cells had slower epithelial repair in response to bleomycin treatment.

To verify that $\gamma \delta$ T cells are required for the resolution of fibrosis, $\gamma \delta$ T cells were adoptively transferred into $\gamma \delta$ $\mathrm{KO}$ mice. There are seven subsets of $\gamma \delta \mathrm{T}$ cells in mice. These subsets have organ specificity and differential roles in inflammation. ${ }^{40}$ To address this, T cells recruited to the lung at a point at which pulmonary $\gamma \delta$ T cells are abundant and fibrotic resolution is beginning were puri- fied. Restoration of $\gamma \delta \mathrm{T}$ cells in the lungs of $\gamma \delta \mathrm{KO}$ mice was sufficient to reverse the enhanced fibrosis seen in $\gamma \delta$ $\mathrm{KO}$ mice.

To develop a mechanistic understanding of how $\gamma \delta \mathrm{T}$ cells reduce fibrosis cytokines, chemokines and growth factors secreted by recruited $\gamma \delta$ T cells were measured. Previous studies ${ }^{37,38}$ have shown that $\gamma \delta$ T cells promote epithelial repair in skin and intestine through the production of fibroblast growth factor 7, also known as keratinocyte growth factor. However, similar to other pulmonary injury models, ${ }^{22,36}$ the current study did not detect any differences in keratinocyte growth factor between $\gamma \delta \mathrm{KO}$ mice and WT mice (data not shown). However, cytokine and chemokine analysis of lung homogenate demonstrated that $\gamma \delta \mathrm{KO}$ mice were deficient in the chemokines CXCL1, IL-6, G-CSF, and CXCL10. Furthermore, overnight culture of positively sorted $\gamma \delta$ T cells purified from whole lung 17 days after bleomycin treatment showed that $\gamma \delta$ T cells were potent producers of CXCL10, CXCL1, and IL-6. Although our positive selection strategy for identifying and sorting $\gamma \delta \mathrm{T}$ cells $\left(\mathrm{GL} 3^{+} / \mathrm{TCR} \beta^{-}\right)$may have potentially activated the $\gamma \delta \mathrm{T}$ cells, these in vitro data, taken together with the cytokine analysis from the $\gamma \delta \mathrm{KO}$ mice, suggest that $\gamma \delta \mathrm{T}$ cells are a major source of CXCL10, CXCL1, IL-6, and G-CSF in the lung. All four factors produced by lung $\gamma \delta \mathrm{T}$ cells (ie, G-CSF, IL-6, CXCL1, and CXCL10) are major chemotactic and inflammatory cytokines. Although the absence of these factors most likely explains the reduced inflammation seen in the BAL fluid of $\gamma \delta \mathrm{KO}$ mice, it does not explain the enhanced severity of fibrosis observed in $\gamma \delta \mathrm{KO}$ mice.

In models of hypersensitivity pneumonitis, mice lacking $\gamma \delta \mathrm{T}$ cells develop more severe inflammation and subsequent fibrosis. ${ }^{24,41}$ This is in contrast to the $\gamma \delta \mathrm{KO}$ response to bleomycin, in which there is a decrease in inflammatory cells in the BAL fluid. However, histological features demonstrate pronounced hypercellularity and intimal thickening in lung parenchyma. Braun et al ${ }^{36}$ have shown that $\gamma \delta \mathrm{KO}$ mice have greater volume density (a measure of alveolar septal thickening) after bleomycin exposure. It is likely that the inflammatory differences seen between $\gamma \delta \mathrm{KO}$ mice and WT mice are compartmental, and these findings suggest that $\gamma \delta \mathrm{T}$ cells are 
required for the migration of inflammatory cells from the intima to the alveolar spaces.

Although the role for T cells in fibrosis is complex, there is evidence that a Th1 bias is beneficial because T-bet KO mice (a Th1 transcription factor) ${ }^{15}$ and GATA-3 overexpressers (a Th2 transcription factor) have enhanced fibrosis. ${ }^{14} \gamma \delta$ T cells are unique in that they are capable of producing Th1, Th2, and Th17 cytokines. ${ }^{42}$ In the current study, the most prominent cytokine produced by $\gamma \delta \mathrm{T}$ cells in culture was the Th1 cytokine CXCL10.

The chemokine CXCL10 is a potent chemoattractant for T lymphocytes, natural killer cells, and monocytes. CXCL10 functions through the chemokine receptor CXCR3; as its name suggests, it is strongly up-regulated by interferon $\gamma$. Although it has strong inflammatory roles, CXCL10 has been implicated in wound healing. Luster and colleagues ${ }^{43}$ first demonstrated its importance in the skin. Mice overexpressing CXCL10 in keratinocytes had delayed wound healing and disorganized granulation tissue. ${ }^{43}$ In the lung, Keane et $\mathrm{al}^{44}$ showed that intramuscular injection of CXCL10 decreased (albeit slightly) bleomycin-induced fibrosis. More recently, it was shown that mice lacking the chemokine receptor for CXCL10 (CXCR3) have increased mortality and a more severe fibroproliferative response to bleomycin. ${ }^{32}$ Given that there are several ligands for this receptor, Tager and colleagues $^{31}$ were able to show that the attenuation of fibrosis was specific to CXCL10 and not other CXCR3 ligands; more interestingly, CXCL10 attenuated fibrosis by inhibiting fibroblast recruitment. These data are supported by data from human IPF tissues in which fibroblasts cultured from IPF samples have decreased levels of CXCL10 compared with non-IPF tissues because of epigenetic dysregulation. ${ }^{45}$ Our own in silico analysis of the public Gene Expression Omnibus database (GDS1252) found that the genes for TCRg, TCRd, and CXCL10 are all expressed in the tissues of patients with IPF. However, these data do not offer any insight into the functionality of $\gamma \delta$ T cells and CXCL10 in humans.

In the present study, several lines of evidence suggest that $\gamma \delta$ T-cell-derived CXCL10 is required for resolution of fibrosis. $\gamma \delta \mathrm{T}$ cells are potent producers of CXCL10 ex vivo, and mice lacking $\gamma \delta$ T cells have reduced CXCL10 levels and severe unresolving fibrosis. Transient expression of $\mathrm{CxC} / 10$ in $\gamma \delta \mathrm{KO}$ mice reduced fibrosis. More important, although adoptive transfer of $\gamma \delta$ T cells into $\gamma \delta$ $\mathrm{KO}$ mice restored levels of CXCL10 and reduced fibrosis, this did not occur with $\gamma \delta \mathrm{T}$ cells from $\mathrm{Cxcl} 10 \mathrm{KO}$ mice.

Although airway epithelial cells are commonly thought to be an important source of CXCL10, the production of CXCL 10 by $\gamma \delta$ T cells is intriguing, given their increased populations in the interstitial space after bleomycin exposure. ${ }^{36}$ Their location in the interstitial compartment places them in close proximity to fibroblasts, collagen involved in collagen deposition, and lesion formation. Interestingly, $\gamma \delta$ T cells are capable of preferentially adhering to fibroblasts. ${ }^{46,47}$ By locally producing CXCL10 in the interstitial space, $\gamma \delta \mathrm{T}$ cells are able to begin the resolution phase of fibrosis seen in the mouse-bleomycin model.
Although our data support a role for $\gamma \delta$-produced CXCL10 in the resolution of fibrosis, we acknowledge that this is probably not the only cytokine involved in fibrotic resolution in mice. Recently, much attention has been given to $\gamma \delta$ T cells and their ability to produce IL-17. ${ }^{16,17}$ Braun et $\mathrm{al}^{36}$ showed that $\gamma \delta \mathrm{T}$ cells are a dominant source of $\mathrm{IL}-17$ and suggested that $\mathrm{IL}-17$ may be involved in epithelial repair responses after bleomycin exposure. This seems unlikely to be the case given the more recent findings that IL-17 $\mathrm{A}^{-1-}$ mice are less sensitive to excessively high doses of bleomycin, ${ }^{16}$ suggesting that IL-17A is proinflammatory and profibrotic. Moreover, Sonnenberg et $\mathrm{al}^{17}$ demonstrated that, although $\gamma \delta \mathrm{T}$ cells do produce IL-17A in response to bleomycin, $\alpha \beta$ T cells are the more dominant source and IL-17A production may suppress the wound repair response by preventing the antiapoptotic effects of IL-22. ${ }^{17}$ In all three studies, sorted T cells were stimulated with phorbol myristate acetate and ionomycin or CD3 beads in vitro. This is different from our studies in which we did not stimulate $\gamma \delta$ T cells in vitro. However, both Sonnenberg and Wilson and colleagues ${ }^{16}$ used lethal doses of bleomycin to induce IL-17-producing T cells. Although we were unable to measure any IL-17 in lung homogenate or cell culture, it still may have been present; perhaps at higher concentrations of bleomycin, we would detect IL-17. We used a pharmaceutical grade of bleomycin, similar to that used by Sonnenberg et al (NOVAPLUS Pharmaceuticals, Irving, TX); in their work, they demonstrate $\alpha \beta$ T cells as the major source of IL-17. This is different from Wilson et al, who used research-grade bleomycin (EMD Chemicals, Gibbstown, $\mathrm{NJ}$ ), which is only greater than $90 \%$ pure. Perhaps impurities found in different grades of bleomycin are capable of activating different subsets of IL-17-producing T cells.

This results in an interesting role for IL-17A in fibrosis. At higher concentrations and more long-term models, such as hypersensitivity pneumonitis, ${ }^{24,41}$ IL-17 may lead to a more protracted inflammatory state. In shorter-term "single-hit" models, such as bleomycin and silica, ${ }^{48}$ in which IL-17 production is limited, IL-17 may have a less inflammatory role. Furthermore, $\mathrm{IL}-17$ is capable of inducing all three CXCR-3 family members (ie, CXCL9, CXCL10, and CXCL11) because they have transcription factor-binding patterns associated with IL-17-induced genes. ${ }^{49}$ This ability to induce antifibrotic cytokines suggests that in response to bleomycin, IL-17 may have a dual role.

Although $\gamma \delta \mathrm{T}$ cells carry antigen receptors on their surface, they are not considered to be classically T-cell receptor activated. ${ }^{40}$ In fact, there is little understanding in the literature as to how $\gamma \delta \mathrm{T}$ cells are stimulated in response to injury. Studies have shown that $\gamma \delta$ T cells may recognize "self" ligands, such as CD1c, ${ }^{50-52}$ T10 and $\mathrm{T}_{22,}{ }^{53}$ and $\mathrm{MHC}$ class I related chains $\mathrm{A}$ and $\mathrm{B}^{54}$; as well as stress proteins, such as heat shock proteins $60^{55,56}$ and $70 .{ }^{57}$ In humans, $\gamma \delta$ T cells have also been stimulated by various phosphoantigens. ${ }^{58}$ Given the antifibrotic nature of $\gamma \delta$ T cells demonstrated in our study and evidence that $\gamma \delta \mathrm{T}$ cells are decreased in the BAL 
fluid of patients with IPF, 20 understanding the mechanisms for stimulating various populations of $\gamma \delta \mathrm{T}$ cells will be important.

In summary, the data presented in this study provide strong evidence that $\gamma \delta$ T cells are integral cells in the resolution of bleomycin-induced injury and fibrosis. Their populations increase in response to injury; through the focal production of large amounts of CXCL10, they aid in the resolution of fibrosis.

\section{References}

1. Mannino DM, Etzel RA, Parrish RG: Pulmonary fibrosis deaths in the United States, 1979-1991: an analysis of multiple-cause mortality data. Am J Respir Crit Care Med 1996, 153:1548-1552

2. Zisman DA, Keane MP, Belperio JA, Strieter RM, Lynch JP 3rd: Pulmonary fibrosis. Methods Mol Med 2005, 117:3-44

3. Raghu G, Weycker D, Edelsberg J, Bradford WZ, Oster G: Incidence and prevalence of idiopathic pulmonary fibrosis. Am J Respir Crit Care Med 2006, 174:810-816

4. Sleijfer S: Bleomycin-induced pneumonitis. Chest 2001, 120:617-624

5. Katzenstein AL, Zisman DA, Litzky LA, Nguyen BT, Kotloff RM: Usual interstitial pneumonia: histologic study of biopsy and explant specimens. Am J Surg Pathol 2002, 26:1567-1577

6. Costabel U, Guzman J: Bronchoalveolar lavage in interstitial lung disease. Curr Opin Pulm Med 2001, 7:255-261

7. Ahmed A, Chang CC: Chronic idiopathic myelofibrosis: clinicopathologic features, pathogenesis, and prognosis. Arch Pathol Lab Med 2006, 130:1133-1143

8. Sharma SK, MacLean JA, Pinto C, Kradin RL: The effect of an antiCD3 monoclonal antibody on bleomycin-induced lymphokine production and lung injury. Am J Respir Crit Care Med 1996, 154:193200

9. Lossos IS, Or R, Ginzburg V, Christensen TG, Mashriki Y, Breuer R: Cyclosporin A upmodulates bleomycin-induced pulmonary fibrosis in BALB/c mice. Respiration 2002, 69:344-349

10. Helene M, Lake-Bullock V, Zhu J, Hao H, Cohen DA, Kaplan AM: T cell independence of bleomycin-induced pulmonary fibrosis. J Leukoc Biol 1999, 65:187-195

11. Corsini E, Luster MI, Mahler J, Craig WA, Blazka ME, Rosenthal GJ: A protective role for $\mathrm{T}$ lymphocytes in asbestos-induced pulmonary inflammation and collagen deposition. Am J Respir Cell Mol Biol 1994, 11:531-539

12. Furuie $H$, Yamasaki $H$, Suga $M$, Ando $M$ : Altered accessory cell function of alveolar macrophages: a possible mechanism for induction of Th2 secretory profile in idiopathic pulmonary fibrosis. Eur Respir J 1997, 10:787-794

13. Jakubzick C, Choi ES, Kunkel SL, Evanoff H, Martinez FJ, Puri RK, Flaherty KR, Toews GB, Colby TV, Kazerooni EA, Gross BH, Travis WD, Hogaboam CM: Augmented pulmonary IL-4 and IL-13 receptor subunit expression in idiopathic interstitial pneumonia. J Clin Pathol 2004, 57:477-486

14. Kimura T, Ishii $Y$, Yoh K, Morishima $Y$, lizuka T, Kiwamoto T, Matsuno Y, Homma S, Nomura A, Sakamoto T, Takahashi S, Sekizawa K: Overexpression of the transcription factor GATA-3 enhances the development of pulmonary fibrosis. Am J Pathol 2006, 169:96-104

15. Xu J, Mora AL, LaVoy J, Brigham KL, Rojas M: Increased bleomycininduced lung injury in mice deficient in the transcription factor T-bet. Am J Physiol Lung Cell Mol Physiol 2006, 291:L658-L667

16. Wilson MS, Madala SK, Ramalingam TR, Gochuico BR, Rosas IO, Cheever AW, Wynn TA: Bleomycin and IL-1beta-mediated pulmonary fibrosis is IL-17A dependent. J Exp Med 2010;207:535-552

17. Sonnenberg GF, Nair MG, Kirn TJ, Zaph C, Fouser LA, Artis D: Pathological versus protective functions of IL-22 in airway inflammation are regulated by IL-17A. J Exp Med 2010;207:1293-1305

18. Wands JM, Roark CL, Aydintug MK, Jin N, Hahn YS, Cook L, Yin X, Dal Porto J, Lahn M, Hyde DM, Gelfand EW, Mason RJ, O'Brien RL, Born WK: Distribution and leukocyte contacts of gammadelta $T$ cells in the lung. J Leukoc Biol 2005, 78:1086-1096

19. Jameson J, Havran WL: Skin gammadelta T-cell functions in homeostasis and wound healing. Immunol Rev 2007, 215:114-122
20. Selman M, Pardo A: Role of epithelial cells in idiopathic pulmonary fibrosis: from innocent targets to serial killers. Proc Am Thorac Soc 2006, 3:364-372

21. Koohsari H, Tamaoka M, Campbell HR, Martin JG: The role of gamma delta $T$ cells in airway epithelial injury and bronchial responsiveness after chlorine gas exposure in mice. Respir Res 2007, 8:21

22. King DP, Hyde DM, Jackson KA, Novosad DM, Ellis TN, Putney L, Stovall MY, Van Winkle LS, Beaman BL, Ferrick DA: Cutting edge: protective response to pulmonary injury requires gamma delta $T$ Iymphocytes. J Immunol 1999, 162:5033-5036

23. Braun RK, Sterner-Kock A, Kilshaw PJ, Ferrick DA, Giri SN: Integrin alpha $\mathrm{E}$ beta 7 expression on BAL CD4+, CD8+, and gamma delta T-cells in bleomycin-induced lung fibrosis in mouse. Eur Respir $J$ 1996, 9:673-679

24. Simonian PL, Roark CL, Diaz del Valle F, Palmer BE, Douglas IS, Ikuta K, Born WK, O'Brien RL, Fontenot AP: Regulatory role of gammadelta $\mathrm{T}$ cells in the recruitment of CD4+ and CD8+ T cells to lung and subsequent pulmonary fibrosis. J Immunol 2006, 177:4436-4443

25. McKinley L, Alcorn JF, Peterson A, Dupont RB, Kapadia S, Logar A Henry A, Irvin CG, Piganelli JD, Ray A, Kolls JK: TH17 cells mediate steroid-resistant airway inflammation and airway hyperresponsiveness in mice. J Immunol 2008, 181:4089-4097

26. McKinley L, Logar AJ, McAllister F, Zheng M, Steele C, Kolls JK: Regulatory $T$ cells dampen pulmonary inflammation and lung injury in an animal model of pneumocystis pneumonia. J Immunol 2006, 177: 6215-6226

27. Zeng X, Moore TA, Newstead MW, Deng JC, Lukacs NW, Standiford TJ: IP-10 mediates selective mononuclear cell accumulation and activation in response to intrapulmonary transgenic expression and during adenovirus-induced pulmonary inflammation. J Interferon Cytokine Res 2005, 25:103-112

28. Fattman CL, Tan RJ, Tobolewski JM, Oury TD: Increased sensitivity to asbestos-induced lung injury in mice lacking extracellular superoxide dismutase. Free Radic Biol Med 2006, 40:601-607

29. Takada H, Matsuzaki G, Yoshida H, Sumichika H, Nomoto K: Functional difference between Thy-1-positive and Thy-1-negative gamma delta T cells induced by Escherichia coli infection in mice. Immunology 1996, 88:261-268

30. Woessner JF Jr: The determination of hydroxyproline in tissue and protein samples containing small proportions of this imino acid. Arch Biochem Biophys 1961, 93:440-447

31. Tager AM, Kradin RL, LaCamera P, Bercury SD, Campanella GS, Leary CP, Polosukhin V, Zhao LH, Sakamoto H, Blackwell TS, Luster AD: Inhibition of pulmonary fibrosis by the chemokine IP-10/CXCL10. Am J Respir Cell Mol Biol 2004, 31:395-404

32. Jiang D, Liang J, Hodge J, Lu B, Zhu Z, Yu S, Fan J, Gao Y, Yin Z, Homer R, Gerard C, Noble PW: Regulation of pulmonary fibrosis by chemokine receptor CXCR3. J Clin Invest 2004, 114:291-299

33. McAllister F, Ruan S, Steele C, Zheng M, McKinley L, Ulrich L, Marrero L, Shellito JE, Kolls JK: CXCR3 and IFN protein-10 in Pneumocystis pneumonia. J Immunol 2006, 177:1846-1854

34. Luzina IG, Todd NW, lacono AT, Atamas SP: Roles of T Iymphocytes in pulmonary fibrosis. J Leukoc Biol 2008, 83:237-244

35. Kim JH, Kim HY, Kim S, Chung JH, Park WS, Chung DH: Natural killer $\mathrm{T}$ (NKT) cells attenuate bleomycin-induced pulmonary fibrosis by producing interferon-gamma. Am J Pathol 2005, 167:1231-1241

36. Braun RK, Ferrick C, Neubauer P, Sjoding M, Sterner-Kock A, Kock M, Putney L, Ferrick DA, Hyde DM, Love RB: IL-17 producing gammadelta $T$ cells are required for a controlled inflammatory response after bleomycin-induced lung injury. Inflammation 2008, 31:167-179

37. Chen Y, Chou K, Fuchs E, Havran WL, Boismenu R: Protection of the intestinal mucosa by intraepithelial gamma delta T cells. Proc Natl Acad Sci U S A 2002, 99:14338-14343

38. Jameson J, Ugarte K, Chen N, Yachi P, Fuchs E, Boismenu R, Havran WL: A role for skin gammadelta T cells in wound repair. Science 2002 , 296:747-749

39. Komori HK, Meehan TF, Havran WL: Epithelial and mucosal gamma delta T cells. Curr Opin Immunol 2006, 18:534-538

40. Born WK, Jin N, Aydintug MK, Wands JM, French JD, Roark CL, O'Brien RL: gammadelta T lymphocytes-selectable cells within the innate system? J Clin Immunol 2007, 27:133-144

41. Simonian PL, Roark CL, Born WK, O'Brien RL, Fontenot AP: Gammadelta $T$ cells and Th17 cytokines in hypersensitivity pneumonitis and lung fibrosis. Transl Res 2009, 154:222-227 
42. Roark CL, Simonian PL, Fontenot AP, Born WK, O'Brien RL: gammadelta T cells: an important source of IL-17. Curr Opin Immunol 2008 20:353-357

43. Luster AD, Cardiff RD, MacLean JA, Crowe K, Granstein RD: Delayed wound healing and disorganized neovascularization in transgenic mice expressing the IP-10 chemokine. Proc Assoc Am Physicians 1998, 110:183-196

44. Keane MP, Belperio JA, Arenberg DA, Burdick MD, Xu ZJ, Xue YY, Strieter RM: IFN-gamma-inducible protein-10 attenuates bleomycininduced pulmonary fibrosis via inhibition of angiogenesis. J Immunol 1999, 163:5686-5692

45. Coward WR, Watts K, Feghali-Bostwick CA, Jenkins G, Pang L: Repression of IP-10 by interactions between histone deacetylation and hypermethylation in idiopathic pulmonary fibrosis. Mol Cell Biol 2010;30:2874-2886

46. Nakajima S, Roswit WT, Look DC, Holtzman MJ: A hierarchy for integrin expression and adhesiveness among $T$ cell subsets that is linked to TCR gene usage and emphasizes $V$ delta 1+ gamma delta T cell adherence and tissue retention. J Immunol 1995, 155:11171131

47. White B, Korn JH, Piela-Smith TH: Preferential adherence of human gamma delta, CD8+, and memory T cells to fibroblasts. J Immunol 1994, 152:4912-4918

48. Lo Re S, Dumoutier L, Couillin I, Van Vyve C, Yakoub Y, Uwambayinema F, Marien B, van den Brûle S, Van Snick J, Uyttenhove C, Ryffel B, Renauld JC, Lison D, Huaux F: IL-17A-producing gammadelta T and Th17 lymphocytes mediate lung inflammation but not fibrosis in experimental silicosis. J Immunol 2010;184:6367-6377

49. Khader SA, Bell GK, Pearl JE, Fountain JJ, Rangel-Moreno J, Cilley GE, Shen F, Eaton SM, Gaffen SL, Swain SL, Locksley RM, Haynes L, Randall TD, Cooper AM: IL-23 and IL-17 in the establishment of protective pulmonary CD4+ $T$ cell responses after vaccination and during Mycobacterium tuberculosis challenge. Nat Immunol 2007, 8:369-377
50. Russano AM, Bassotti G, Agea E, Bistoni O, Mazzocchi A, Morelli A, Porcelli SA, Spinozzi F: CD1-restricted recognition of exogenous and self-lipid antigens by duodenal gammadelta + T lymphocytes. J Immunol 2007, 178:3620-3626

51. Spada FM, Grant EP, Peters PJ, Sugita M, Melian A, Leslie DS, Lee HK, van Donselaar E, Hanson DA, Krensky AM, Majdic O, Porcelli SA, Morita CT, Brenner MB: Self-recognition of CD1 by gamma/ delta T cells: implications for innate immunity. J Exp Med 2000, 191:937-948

52. Leslie DS, Vincent MS, Spada FM, Das H, Sugita M, Morita CT, Brenner MB: CD1-mediated gamma/delta T cell maturation of dendritic cells. J Exp Med 2002, 196:1575-1584

53. Adams EJ, Strop P, Shin S, Chien YH, Garcia KC. An autonomous CDR3delta is sufficient for recognition of the nonclassical MHC class I molecules T10 and T22 by gammadelta T cells. Nat Immunol 2008 , 9:777-784

54. Wrobel $P$, Shojaei $H$, Schittek B, Gieseler F, Wollenberg B, Kalthoff $H$ Kabelitz D, Wesch D: Lysis of a broad range of epithelial tumour cells by human gamma delta T cells: involvement of NKG2D ligands and T-cell receptor- versus NKG2D-dependent recognition. Scand J Immunol 2007, 66:320-328

55. Chen $\mathrm{H}$, He X, Wang Z, Wu D, Zhang H, Xu C, He H, Cui L, Ba D, He $W$ : Identification of human $T$ cell receptor gammadelta-recognized epitopes/proteins via CDR3delta peptide-based immunobiochemical strategy. J Biol Chem 2008, 283:12528-12537

56. Wadia P, Atre N, Pradhan T, Mistry R, Chiplunkar S: Heat shock protein induced TCR gammadelta gene rearrangements in patients with oral cancer. Oral Oncol 2005, 41:175-182

57. Zhang $\mathrm{H}, \mathrm{Hu} \mathrm{H}$, Jiang $\mathrm{X}$, He H, Cui L, He W: Membrane HSP70: the molecule triggering gammadelta $T$ cells in the early stage of tumorigenesis. Immunol Invest 2005, 34:453-468

58. Thompson K, Roelofs AJ, Jauhiainen M, Mönkkönen H, Mönkkönen J, Rogers MJ: Activation of gammadelta T cells by bisphosphonates Adv Exp Med Biol 2010;658:11-20 